\title{
PETER RIVIÈRE
}

\section{CARIBISKE \\ SJÆLLEANLIGGENDER \\ - efter Fock}

Niels Focks Waiwai. Religion and Society of an Amazonian Tribe (1963) udgør sammen med Jens Ydes Material Culture of the Waiwái (1965) en sand guldgrube af etnografiske rigdomme om disse caribisktalende folk i 1950'erne i Øvre Essequibo-regionen i det nuværende Guyana. Begge er traditionelle etnografier, i ordets allerbedste betydning, og de dukkede op i en etnografisk ørken. Man behøver blot at se på bibliografierne i disse to bind for at fastslå præcist hvor lidt, der på det tidspunkt var blevet skrevet om det daværende Guiana af ægte antropologisk karakter. ${ }^{1}$ Endvidere er mange af de informationer, der er indeholdt i disse bind, blevet bekræftet og underbygget af senere skribenter, og det er et af disse emner, som er velbeskrevet af Fock, som dette indlæg drejer sig om: menneskesjælen. Hensigten er at gennemgå hvad Fock ${ }^{2}$ har at sige om waiwai-sjælen og dernæst overveje, hvordan dette passer med, hvad der siden dengang er blevet berettet om andre caribisktalende folkeslag.

Først er nogle advarende ord dog på sin plads. Ordet ,sjal“ bruges som en forenklet betegnelse for et komplekst begreb, som unddrager sig definition i den engelsktalende verden. Andre mulige termer, der kunne have været anvendt, er liv, livskraft, essens, ånd og så videre; ingen af disse er dog værre eller bedre end den anden. De misrepræsenterer alle på en eller anden måde de lokale begreber. Det andet punkt er, at jeg begrænser mine overvejelser til menneskesjælen, til trods for at den samme sjæl ofte ses som værende fælles for alle levende væsner, og selv definitionen på, hvad der konstituerer et levende væsen, må undersøges i hvert enkelt tilfælde. Med andre ord, denne artikel handler udelukkende om et lille aspekt af noget, som er et meget omfattende emne, og dermed må den nødvendigvis være ufuldstændig.

\section{Waiwai-sjælen}

Waiwai-ordet for sjæl er ekati, som også betyder skygge, billede, vital kraft. Sjælens hovedsæde er hjertet, men den er spredt ud i hele kroppen og kan også dele sig, lige som en væske, til ting den kommer i kontakt med. Fock rapporterer også, at graden af sjælens forankring $\mathrm{i}$ individet varierer, og han identificerer tre typer af mennesker baseret på dette kriterium. Det drejer sig om shamaner, småbørn og almindelige mennesker. I livet er 
det almindelige menneskes sjæl forankret $\mathrm{i}$ individet, bortset fra i drømme, og tabet af den betyder sygdom eller død. Shamanen, på sin side, har kontrol over sin sjæl og er i stand til af egen vilje at sende den på bes $\emptyset \mathrm{g}$ i andre kosmiske regioner. I kontrast til begge disse er et lille barns sjæl ikke forankret, men løsriver sig ufrivilligt og vandrer frit. Det er i denne periode af et barns liv, at forældrene er underlagt couvaderestriktioner, som delvis drejer sig om konstruktion af personen ved at fastgøre sjælen til kroppen (se Rivière 1974). Det kan også bemærkes, at indtil indvielsen, omkring trettenårsalderen, tiltales en dreng eller en pige som okopuchi, ordret ,lille lig“. En sprogbrug som også antyder det noget midlertidige forhold mellem individet og dets sjæl (14-6, 151-2).

Waiwaierne anerkender også eksistensen af en øjensjæl, men oplysningerne om den er vage, og Fock opgiver ikke, hvorvidt der er et særligt ord for den. Den beskrives som værende ,det lille menneske man altid ser i andres øje“. Ejendommeligt nok, og ulig ekatïen, bliver øjensjælen ,ikke anset for at være en absolut nødvendighed for individet“, selv om dens afgang synes at være et tegn på døden (19-20).

Fock var ikke i stand til at indhente endegyldig information om, hvor det nyfødte barns sjæl kommer fra, selv om den er der ved fødslen, og der er noget der tyder på, at den skabes ved undfangelsen. Focks hovedinformant hævdede, at en drengs sjæl kom fra hans far og en piges fra hendes mor (17).

Et navn, for hvilket der ikke oplyses nogen indfødt term, gives til et spædbarn lige efter fødslen, og det er sædvanligvis navnet på en afdød bedsteforælder eller oldeforælder. Ud over dette familienavn gives barnet også et åndenavn, som shamanen har modtaget fra himmelånden Måne. Imidlertid er forholdet mellem navnet og individet og den grad, hvormed det udgør en integreret del af personen, ikke undersøgt, selv om Fock oplyser, at navne har en ,psykisk“" kvalitet (16-7, 140-1).

Ved døden forlader ekatïen kroppen og bliver til ekatïnho, ordret ,den forhenværende sjæl“". Den fuldstændige betegnelse er ekatïnho-kworokjam eller sjæle-ånd. Der er to slags kworokjam, men det er kun denne form, der har interesse i denne sammenhæng. Den holder til som en usynlig ånd i nærheden af den afdødes grav, selv om den også kan manifestere sig i form af et dyr. På den anden side stiger øjensjælen ved døden op til himlen, hvor den efter at være underkastet pinsler lever et evigt lykkeligt liv (18-20).

Selv om Fock ikke henleder opmærksomheden på det, er der en interessant, om end grov, korrelation mellem måderne, hvorpå man skaffer sig af med et lig, og de typer af folk, der skelnes ved hjælp af graden af deres sjæls forankring. ${ }^{3}$ En shaman, som har en frivilligt uforankret sjæl, begraves, eventuelt med en sjælestige op fra graven; et almindeligt menneske med en forankret sjæl kremeres; et barn med en ufrivilligt uforankret sjæl kremeres, men knoglerne samles under en omvendt potte. ${ }^{4}$ Disse tre forskellige praksiser forekommer også at være kædet sammen med ideerne om sjælens skæbne. Ekatïnhoen, den tidligere sjæl hos et almindeligt menneske, opholder sig permanent på stedet for kremeringen, selv om det står den frit for at vandre enten som en usynlig ånd eller i skikkelse af et dyr. Den frygtes som værende ondsindet og hævngerrig over for folk. På den anden side fortsætter den døde shamans sjæl sammen med hans tjenende ånder til himlen ,hvor alle menes at være glade og venlige“. Det, som er uklart, er hvorfor barnets ubrændte knogler gives en sekundær begravelse; ej heller får vi fortalt, hvad der sker med et barns sjæl ved døden. Ikke desto mindre synes forskellene i begravelsesriter at afspejle waiwaiernes ideer om det varierende forhold mellem krop og sjæl i forhold til forskellige slags mennesker (161-7). 
På basis af denne summariske beretning om Focks detaljerede beskrivelse af waiwaiernes ideer og praksiser er formålet nu at se på andre etnografiske beskrivelser fra regionen, alle post-Fock, og se i hvilket omfang waiwai-materialet stemmer overens med disse. Der begyndes med waiwaiernes $\emptyset$ stlige naboer, trioerne. ${ }^{5}$

Hos trioerne er personen sammensat af krop (pun), sjæl (amore), og navn (eka). Som hos waiwaierne anvender trioerne det sammen ord for sjæl og skygge. Trio-sjælen kan bedst beskrives som et moralsk neutralt begreb, noget i slægt med vores egen opfattelse af bevidsthed, i betydningen totaliteten af tanker og følelser, som konstituerer et menneskes bevidste væren. Det dækker dog mere end dette, i og med at der er grader af bevidsthed, som associeres med status, magt og viden.

Man forestiller sig, at sjælen gennemtrænger kroppen med særlige koncentrationer ved hjertet og pulsstederne såvel som ved leddene, især knæ og ankler. Fors øg på at finde ud af, hvorvidt disse er forskellige aspekter af en enkelt sjæl eller udgør adskillige sjæle, afstedkom et meget variabelt respons. Dog er der, også selv om det samme ord anvendes, en klar genkendelse af en særlig øjensjæl, som er en essentiel livsingrediens, der slukkes ved døden. Dette kontrasterer med Focks påstand om, at blandt waiwaierne er det ikke en af livets ,,absolutte nødvendigheder for individet“, men det stemmer overens med nogle andre eksempler, som jeg om lidt vil tage op, hvor $\emptyset$ jensjælen bliver direkte ligestillet med, hvad der kan oversættes som ,liv“.

På spørgsmålet om, hvornår sjælen tager ophold i et spædbarn, var der yderligere uoverensstemmelser. Nogle sagde, at småbørn modtager deres sjæl gennem fontanellen ved fødslen, hvorimod andre hævdede, at de blev født med deres øjensjæl, men ikke havde nogen anden sjæl før i fire-femårsalderen. Der er, som hos waiwaierne, en vis forestilling om, at kilden til sjælen er kønsbestemt sådan at forstå, at en dreng får den fra sin far, en pige fra sin mor. ${ }^{6}$ Det nyfødte barns sjæl er lille og ikke fastgjort til kroppen, og, medmindre de korrekte rituelle procedurer iagttages af forældrene, det vil sige couvade, er der en stor fare for, at sjælen vil forvilde sig bort fra spædbarnet. En del af forklaringen på dette er det substansfællesskab, der tænkes at eksistere mellem forældre og børn, således at de førstnævntes aktiviteter påvirker de sidstnævntes velbefindende. Denne idé er mere generel end som så,og substansfællesskabet menes også at bestå mellem mand og kone og i varierende grad blandt andre slægtninge. Det der deles er sjælen eller essensen, således at dem, man har fælles substans med, påvirkes af ens handlinger, og deres påvirker én selv af. Med andre ord er et menneskes sjæl ikke fuldstændig adskilt fra andres sjæle.

Efterhånden som trio-barnet vokser op, bliver sjælen gradvist mere forankret til kroppen, men selv hos den voksne er dette aldrig fuldstændigt. Sjælen forlader kroppen i drømme, og dette opfattes som normalt. Faktisk betyder den lokale term for at drømme ordret , at forsyne sig selv med en sjæl“". Det er derimod unormalt, når sjælen er fraværende fra kroppen under andre forhold, først og fremmest under sygdom. Pladshensyn tillader mig ikke at overveje trio-ætiologi i dybden, men som med de fleste andre folk i regionen ligger årsagerne i den usynlige verden, og det er dér, man skal søge for at forstå den synlige verdens tildragelser. De er resultatet af den menneskelige aktivering af ånder eller af direkte åndeintervention, eller en kombination af begge. Én diagnose på sygdom er sjæletab, og her bliver skillelinjen mellem sygdom og død udflydende - tilstanden hos en bevidstløs person, der er i koma eller er død, beskrives med det samme ord, wakenai. Den ordrette oversættelse af denne term er ,er ikke“, og svaret på spørgsmålet, ,hvad er ikke?", er sjælen. Dette afspejler den opfattede forbindelse mellem tilstandene sygdom 
og død, da de begge er tilstande, hvor sjælen og kroppen er svagt forbundne. Godt helbred manifesteres på den anden side som et fast forankret forhold mellem krop og sjæl, personens hårdhed (se Rivière 1969:262-3).

Døden tilvejebringer et privilegeret øjeblik, hvorunder man kan erkende sjælen som det, den er, når personen er usamlet, om jeg så må sige. Jeg vil behandle trioernes eskatologiske overbevisninger ganske kort. Ved dødens indtræden bliver den jordiske krop skaffet af vejen, traditionelt begravet i gulvet under huset, som derefter forlades. Det er dog ikke så sikkert, hvad der sker med sjælen eller sjælene, som nu er blevet til amorempë eller ,den forhenværende sjæl“. Ud fra de modstridende udtalelser jeg fik, fremstår det, som om en del af sjælen for en tid holder til blandt de overlevende og forsøger at lokke dem væk, hvorimod øjensjælen tager af sted på en hasarderet rejse gennem himlen til amore entuhtao på den østlige horisont, hvor himmel og hav mødes. Termen entu betyder ,ejer“, „,kilde“, ,rod“" eller „oprindelse“, og -htao er en efterstilling, der betyder ,i“". De beskrivelser, jeg fik af dette sted, er langt fra klare, men det synes at være som en sø af sjælestof, et sjælereservoir. Ved dødens indtræden flyder sjælen tilbage i søen og bliver uerkendelig som en enhed. Det synes at være som at hælde en kop vand i en spand med vand. Ved fødslen øses en kop vand op, således at mens en nyfødt kan få nogle partikler fra en eller andens forhenværende sjæl, er chancen for udelukkende at få den samme slags partikler meget lille. Med andre ord, selv om sjælestof genbruges, sådan at enhver særskilt sjæl er sammensat af partikler fra forhenværende sjæle, vil den i sig selv næsten med sikkerhed være unik. I forhold til sjælen er det således svært at tale om reinkarnation, men det, der faktisk bliver reinkarneret, er det aspekt af individet, der er kendetegnet ved et navn.

Navnet er bindeled mellem kroppen og sjælen, eller måske snarere det, der kendetegner den forenede tilstedeværelse af krop og sjæl som en person i den synlige verden. Navne overføres gennem alternerende generationer; en person modtager navnet på et nyligt afdødt medlem af bedsteforældregenerationen. Ved bærerens død bliver navnet midlertidigt herreløst, men det er under disse omstændigheder, at betydningen af navnet i forholdet mellem krop og sjæl bliver fuldt åbenbaret. På trio giver det ingen mening at spørge om navnet på en afdød person - med andre ord bliver et spørgsmål som for eksempel „hvad var din afdøde fars navn?" ikke forstået. Det rigtigt formulerede spørgsmål lyder: „Hvad er din fars afdøde navn?“" Trioerne påpeger meget rimeligt, at bare fordi ens far er død, betyder det ikke, at han er holdt op med at være ens far. Med andre ord, det er ikke forholdet, der er ophørt med at eksistere, men navnet, der kendetegner og sammenbinder krop og sjæl som et levende, synligt, socialt væsen.

\section{Maroni River-caribi-sjælen}

Som et yderligere eksempel vil jeg tage Maroni River-caribierne i Surinam som beskrevet af Kloos (1971) med supplerende information fra Magaña (1988). Selv om de er kraftigt påvirket af kristendommen, kan der skelnes træk svarende til dem, vi har bemærket hos trioerne og waiwaierne. Maroni River-caribierne har ordene a:ka, aka:lïmbo og ekato:nümbo, som Kloos respektivt oversætter med „sjæl“, „forhenværende sjæl“ og „,spøgelse“ ${ }^{7}$ Der er adskillige sjæle, lokaliseret i forskellige dele af kroppen, men Kloos regner dem for at være forskellige manifestationer af en enkelt enhed. Ved døden foreta- 
ger den forhenværende sjæl en hasarderet rejse til himlen, medmindre personen fik en dårlig død, i hvillket tilfælde den forbliver på jorden for at hjemsøge folk. Spøgelset, ekato:nümbo, får eksistens i dødsøjeblikket; nogle hævder, at det er skyggen, som opnår en uafhængig eksistens ${ }^{8}$ og plager de levende med sygdom og død (Kloos 1071:151-2). Imidlertid foreslår Kloos også, at det kun er spøgelser af de mennesker, som fik en dårlig død, som på denne måde er plagsomme (op.cit.:216). Ifølge Magaña, som fortrinsvis benytter sig af tidligere kilder, forestiller kalinaerne sig forskellige sjæle, som er lokaliseret i forskellige dele af kroppen og har forskellige destinationer ved dødens indtræden. Nogle stiger op i himlen, og andre forbliver på jorden forvandlet til dyr og ånder. Faktisk er disse to positioner ikke så forskellige, bortset fra spørgsmålet om, hvorvidt der er en eller flere sjæle, og de har store ligheder med trioernes og waiwaiernes ideer om emnet (Magaña 1988:162).

En yderligere slående lighed med waiwaierne er det forhold, at Maroni River-caribiernes begravelsespraksiser veksler i forhold til, hvorvidt den afdøde er et spædbarn, et almindeligt menneske eller en shaman (Kloos 1971:146-7). Her er det ikke måden, hvorpå man skaffer sig af med liget, som varierer, men graden hvormed begravelsen elaboreres. Alle begraves nu på kirkegården, selv om det tidligere fandt sted i eller nær ved huset, og en gammel kano blev brugt som kiste. For både almindelige mennesker og shamaner afholdes der en vågenat, selv om der i det sidste tilfælde synges andre slags sange (åndesange) af en forsamling af shamaner. For et spædbarn afholdes der ingen natlig fest, og begravelsen foregår uden megen ceremoni eller offentlig opmærksomhed. Selv om det ikke nævnes direkte, forekommer det rimeligt at antage, at der ligeledes i spædbørns tilfælde ikke afholdes nogen af de to yderligere fester, der fejres for ældre mennesker. Uanset om nogen af disse fester traditionelt indebar en sekundær begravelse, gør ingen af dem det i dag, og Kloos fortolker dem som dels en mindefest for de døde, dels en markering af den gradvise udfasning af sorgen (op.cit.:147-51).

Et lille barn har intet navn (e:tii) i nogen tid, selv om Kloos ikke specificerer hvor længe. Barnet navngives af en bedstemor på mødrene side, som siges at drømme det. Disse navne siges desuden at være gamle (op.cit.:104). Der er intet her, der modsiger de to tidligere eksempler, men man kan overveje, hvorvidt den uceremonielle behandling af døde børn er begrænset til perioden, før de får navne, eller, i kristne termer, mens de stadig er udøbte.

\section{Kapon-, pemon- og yekuana-sjæle}

Vi befinder os fortsat på velkendt territorium, når vi vender os mod kaponerne og pemonerne i Guyana, Brasilien og Venezuela. ${ }^{9}$ Blandt disse folk forekommer pon, den substans af legemligt kød som skelnes fra esak, som referer til kroppen som helhed. Termen esak har også en betydning af ejerskab til eller kontrol over noget, og dermed forekommer det at have en semantisk overlapning med trio-termen entu. Imidlertid betyder entu ikke krop, ej heller har det ,en betydning af at inkorporere noget“, som esak har. Ånden eller sjælen (akwaru blandt kaponerne og ekaton ${ }^{10}$ blandt pemonerne) optræder som en livskraft og forstås som en del af det strålende lys $(a k w a)$, som strømmer ud fra solen. Dog er dette ikke blot et mekanisk begreb, men har kvalitative og moralske associationer såvel som kvantitative variationer. Således er den, der har mere sjæl eller ånd, mere intel- 
ligent, vidende, klogere og lykkeligere. Akawaerne refererer desuden til en øjensjæl (ewang enu), men i lighed med waiwaierne tillægger de den ikke megen betydning. Endelig kan det bemærkes, at trio-ordet for sjæl, amore, forekommer blandt akawaioerne med den samme betydning, ikke i hverdagssprog, men alene i shamanistiske sange (Butt Colson 1989:53-61; 1990: 13-34; 1997, pers. meddel.).

I en tidligere artikel refererer Butt desuden til begrebet akwarupo, ${ }^{11}$ spøgelse, ordret „,mangler en sjæl“, hvilket antyder, at det kun forekommer ved et menneskes død. Hun fremsætter den pointe, at ved døden drager akwaruen op til himlen, mens akwarupoen bliver tilbage for at hjemsøge folk på jorden. Hun bemærker også, at de ses som værende respektivt god og ond (Butt 1954:52-6). Atter engang har vi et grundrids over et sæt af ideer, der nøje svarer til dem, vi allerede har undersøgt.

Yekuanaerne i det sydlige Venezuela, en anden caribisktalende gruppe af tropisk regnskovsagerbrugere, anerkender eksistensen af seks sjæle, selv om de alle indebærer verbale elaboreringer over en enkelt grundterm, akato, som ordret betyder ,dobbelt" og er afledt af $a k a$, ordet for „to“" ${ }^{12}$ To af dem, øjensjælen (ayenudu akano akato) og hjertesjælen (ayewana akano akato), er indeholdt i kroppen; de repræsenterer evigt liv, rejser ud i drømme og vender tilbage til himlen ved døden. Disse sjæle er uafvendeligt gode og står i kontrast til de andre fire, som er uden for kroppen og er forløsende i den forstand, at de absorberer individets synder. „Sjælen i Månen“ (nuna awono akato) absorberer det meste af et menneskes ondsindethed og brænder for evigt, i modsætning til ,sjælen i Solen“" (Shi awono akato), som har nogen godhed over sig og ved døden vender tilbage til sit hjem i solen. „Sjælen i vandet“ (tuna awono akato) er individets spejling i vandet, hvortil den vender tilbage ved døden, og den anses som næsten lige så ond som Månesjælen. Den sidste sjæl er den, der vedrører Jorden, akatomba, som afslører sig selv som skyggen og efter døden vandrer omkring på jorden i form af en lille dværg, der laver brægelyde (Guss 1989:50-1). Selv om Guss ikke siger det, kan man gætte på, at akatomba betyder „forhenværende akato“ og dermed er ækvivalenten til waiwaiernes spøgelse eller ekatïnho, Maroni River-caribiernes ekato:nimbo, og pemonernes akwarupo.

\section{Konklusioner}

I udvælgelsen af fire eksempler til at sammenligne med waiwaierne er det indlysende at man er selektiv, men i nogen grad har udvælgelsen været ansporet af karakteren af det tilgængelige materiale. Der er mange caribisktalende folkeslag, om hvem vi kun har få eller slet ingen tilgængelige informationer om emnet for denne gennemgang. Derfor kan det ikke udelukkende være et resultat af udvælgelse, at en høj grad af overensstemmelse i ideer er fremkommet. Når man tager de forskellige baggrunde, teoretiske standpunkter og formål hos de pågældende etnografer i betragtning, er sammenfaldet faktisk bemærkelsesværdigt. Et distinkt og grundlæggende mønster forekommer, som består i en sjæl, der er til stede overalt i kroppen, og som er en væsentlig komponent $i$ individets tilværelse som levende. Sjælen kan have mere end et led eller aspekt. Ved døden stiger en del af sjælen til himlen, og en del forbliver på jorden som et spøgelse, selv om sidstnævnte eventuelt kun opstår ved dødens indtræden. Der er en vis sammenhæng mellem den sjæl, der stiger op i himlen, og godhed, og det spøgelse, der forbliver på jorden, og ondsindet- 
hed. Ud over dette er der en vis grad af variation, som kan være et resultat af enten ægte lokale elaboreringer eller forskelle i etnografisk fremstilling.

En af disse vedrører navne. Vi så i trio-materialet, at navnet en essentiel ingrediens i det levende menneske, mens Fock fastslår, at waiwai-navnet har en psykisk komponent. I de andre eksempler forekommer det ikke, som om navnet har denne egenskab, selv om det kan bemærkes, at de stavelser, der danner trio-ordet for navn, eka, atter forekommer i waiwai-ordet for sjæl, ekatï; i Maroni River-caribiernes ord for spøgelse, ekato:nimbo; i pemon-ordet for sjæl, ekaton og sandsynligvis i yecuana-ordet for dobbelt, akato. Dette er måske et sammenfald uden betydning, men det er tankevækkende, især når man overvejer det i sammenhæng med et andet træk ved navne overalt i regionen. Dette er den hemmelighedsfuldhed, hvormed navne tilsløres, hvilket på sin side udspringer af den intime association mellem individer og deres navne. Dette tyder på, at navne, sammen med andre komponenter som kroppen og sjæle, er essentielle komponenter i individuel identitetsdannelse. ${ }^{13}$

Hvis vi kigger ud over de caribisktalendes sfære, finder vi, at blandt mange folkeslag i Sydamerikas lavland er navnet ikke bare et aspekt af personen eller en psykisk komponent, men en komponent i selve psyken. Eksemplerne er særdeles talrige, og jeg vil blot anføre to. Det første er tukano-barasanaerne i det nordvestlige Amazonas, for hvem navnet er sjælen i dens reneste, immaterielle form i kontrast til de sjæle, der forbindes med kroppens bløde organer og knogler (Hugh-Jones 1979:133-4). Det andet er arakmbuterne i Madre de Dios-regionen i Peru. Deres ideer er påfaldende overensstemmende med trioernes; for dem er personen sammensat af krop, sjæl og navn, og sidstnævnte ,udgør en persons essens, idet den binder kroppen og sjælen sammen til en helhed (Gray 1996:80, 81). ${ }^{14}$

Det synes, som om ideer vedrørende sjælen blandt nogle af de caribisktalende folk i Guiana stemmer godt overens med opfattelser, der findes inden for det videre område af tropisk regnskov. Det var Niels Fock, som ved den moderne Amazonasetnografis daggry var den første til så nøjagtigt at skildre disse ideer.

Oversat af Nina Johnsen

\section{Noter}

1. Med ordet Guiana refererer jeg til det geografiske område, som medtager dele af Brasilien, Venezuela, Guyana, Surinam og Fransk Guiana. En tilsvarende situation kan bemærkes blandt tukano-talende folk i det nordvestlige Amazonas, hvor Goldmans The Cubeo (også udgivet i 1963) markerede daggryet for dette områdes involvering i moderne antropologisk litteratur.

2. Alle referencer er til Fock 1963, med mindre andet er angivet.

3. Materialet må nødvendigvis vrides en anelse for at opnå denne korrelation, og forholdene sløres af variation og ydre påvirkninger. Til trods for dette er der noget at komme efter, og som det vil fremgå nedenfor, forekommer der også et andet lignende eksempel i regionen.

4. Det er interessant at bemærke, at da Farabee besøgte waiwaierne i 1913, blev de ubrændte jordiske rester af almindelige waiwaier samlet sammen og anbragt i en potte (Farabee 1924:171-2).

5. Trio-materialet blev indsamlet af forfatteren. 
6. For en mere kompleks og decideret patrilineær teori om undfangelse givet af en trio-shaman, se Rivière (1969:62-3).

7. Kloos (1971:151) bemærker at Penard og Penard i 1907 havde noteret ordet kasoeloe som, ,et menneskes sjæl “ og oplyser, at det er ukendt i den betydning i dag, hvor det betyder ,perle“. Dette er interessant, fordi piaroaerne i Venezuela bruger begrebet ,perler“ til at gengive ideer om bevidsthed og viden (se Overing 1988).

8. Det er ikke klart hvad ekato betyder, eftersom ordet for spøgelse, ekato:nïmbo, klart er afledt af ekato og nïmbo og formodentlig betyder en „forhenværende ekato“. Imidlertid er det ikke lykkedes mig at finde en oversættelse af ekato; Kloos belyser ikke termen, ej heller er den nævnt hos hverken Ahlbrink (1931) eller Hoff (1973).

9. Pemonerne er sammensat af macusierne, taurepanerne, arekunaerne og karamakotoerne, og kaponerne af akawaioerne og patamonaerne.

10. Pemon-ordet ekaton ville betyde ,navne“ på trio, hvorimod Butt Colson ikke omtaler navne som værende en del af personen. Williams (1932:182) opgiver makusi-ordet for hans sjæl som $i-t$-é-katón og hans forhenværende sjæl som I-ka-ton-be. Akawaio-ordet for navn er esik (Audrey Colson 1997, pers. meddel.)

11. I 1954 anvendte Butt „," frem for , , ${ }^{\prime \prime}$ i både akwaru og akwarupo. Det rullede „l“ i caribiske sprog lyder ofte som et , , $\mathrm{r}^{*}$ og kan opfattes som ortografisk ækvivalent.

12. Yekuanaerne opfatter ethvert objekt, levende eller uden liv, som havende en usynlig dobbeltgænger eller akato. I overensstemmelse hermed er dette et meget vigtigt begreb i indretningen af deres univers. Guss (1989:31-61) behandler dette i detaljer i et afsnit med overskriften ,The dual nature of reality“.

13. Audrey Colson, som har givet nogle meget hjælpsomme kommentarer til dette indlæg, følte, at der sandsynligvis er mere vedrørende navne blandt akawaioerne, end det havde været muligt at finde ud af på grund af deres høje grad af hemmelighedsfuldhed omkring dem.

14. For hele Grays diskussion af dette anliggende, se hans kapitel 6, der meget passende har overskriften „Keeping Body and Soul Together“ (Gray 1996).

\section{Litteratur}

Ahlbrinck, W.

1931 Encyclopaedia der Karaiben. Verhandelingen der Koninklijke Akademie van Wetenschappen: Amsterdam.

Butt, A. J.

1954 The Burning Fountain from Whence it Came. Timehri: The Journal of the Royal Agricultural and Commercial Society of British Guiana 33:48-60.

1989 La naturaleza del ser. Conceptos fundamentales de los Kapón y Pemón. Las Religiones Amerindias: 500 años después. Quito: Ediciones Abya-Yala.

Butt Colson, A. J. \& Cesáreo de Armellada.

$1990 \quad$ El rol económico del chamán y su base conceptual entre los Kapones y Pemones septentrionales de las Guayanas. Montalban 22:7-97.

Farabee, W. C.

1924 The Central Caribs. The University Museum: University of Pennsylvania.

Fock, N.

1963 Waiwai: Religion and Society of an Amazonian Tribe. Copenhagen: The National Museum.

Goldman, I.

1963

The Cubeo. Indians of the Northwest Amazon. Urbana: University of Illinois Press.

Gray, A.

1996 The Arakmbut: Mythology, Spirituality and History in an Amazonian Community. Providence \& Oxford: Berghahn Books. 
Guss, D. M.

1990 To Weave and Sing. Art, Symbol, and Narrative in the South American Rain Forest.

Berkeley, Los Angeles, London: University of California Press.

Hoff, B. J.

1968 The Carib Language. 'S Gravenhage: M. Nijhoff.

Hugh-Jones, C.

1979 From the Milk River. Spatial and Temporal Processes in Northwest Amazonia. Cambridge University Press.

Kloos, P.

1971

The Maroni River Caribs of Surinam. Assen: Van Gorcum.

Magaña, E.

1988

Orión y la mujer Pléyades. Simbolismo astronómico de los indios kalina de Surinam.

Dordrecht, Providence: Foris Publications.

Overing, J.

1988 Personal Autonomy and the Domestication of the Self in Piaroa Society. I: G Jahoda \& I Lewis (eds.): Acquiring Culture: Ethnographic Perspectives on Cognitive Development. London: Croom Helm.

Rivière, P.G.

1969

Marriage among the Trio. Oxford: The Clarendon Press.

1974

The Couvade: A Problem Reborn. Man 9:423-35.

Williams, J.

1932

Grammar Notes and Vocabulary of the Language of the Makuchi Indians of Guiana.

Collection Internationale de Monographies Linguistiques 8.

Yde, J.

1965

Material Culture of the Waiwái. Copenhagen: The National Museum. 
